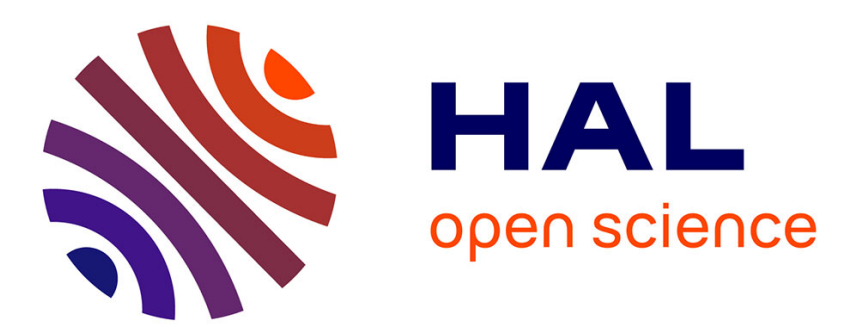

\title{
Professionalization in safety: a study of the professional context of a post master safety program's alumni
}

Wim van Wassenhove, Christian Foussard

\section{To cite this version:}

Wim van Wassenhove, Christian Foussard. Professionalization in safety: a study of the professional context of a post master safety program's alumni. ESREL European Safety and Reliability Conference, Jun 2018, Trondheim, Norway. hal-03384912

HAL Id: hal-03384912

https://hal-mines-paristech.archives-ouvertes.fr/hal-03384912

Submitted on 19 Oct 2021

HAL is a multi-disciplinary open access archive for the deposit and dissemination of scientific research documents, whether they are published or not. The documents may come from teaching and research institutions in France or abroad, or from public or private research centers.
L'archive ouverte pluridisciplinaire HAL, est destinée au dépôt et à la diffusion de documents scientifiques de niveau recherche, publiés ou non, émanant des établissements d'enseignement et de recherche français ou étrangers, des laboratoires publics ou privés. 


\title{
Professionalization in safety: a study of the professional context of a post master safety program's alumni
}

\author{
Wim VAN WASSENHOVE \\ PhD, Assistant Professor \\ MINES ParisTech \\ PSL Research University \\ CRC - Centre de recherche sur les risques et les crises \\ CS 10207 rue Claude Daunesse \\ 06904 Sophia Antipolis Cedex, France \\ wim.van_wassenhove@mines-paristech.fr \\ Christian FOUSSARD \\ Consultant Risk Management \& Process Safety \\ Senior Lecturer \\ Dubai Festival City,
Dubai United Arab Emirates
christian.foussard@mines-paristech.org
}

\begin{abstract}
Our contribution to the ESREL conference will present the first results of a qualitative and quantitative study on the professionalization of alumni of a post master safety program. The post master Management of Industrial Risks has graduated 197 students since 2004.

We addressed an online questionnaire to all the alumni, five in depth interviews will be realized with alumni and their work colleagues and a focus group discussion will be held.

The online questionnaire will investigate their careers (company, position and wages) but also how safety is organized in their company, with whom they interact, what are their missions. For the job missions, we focus on their personal convictions, the importance given by their organization or company and the real time spent doing the job missions. We will also investigate the characteristics of their work conditions and what are, from their own point of view, the real contributions for safety in their organization. Finally, the knowledge and competencies they mobilize or want to mobilize doing their job will be assessed.
\end{abstract}

Those findings intend to, firstly, dress a picture of the safety professional daily job, secondly, identify factors that shape the safety professional's role in the organization and, finally, elaborate a more adapted curriculum for the training and development of future safety professionals. 
Keywords: professionalization in safety, safety trainings, safety education programs

\section{Introduction}

The safety science is a rather young science. As it is a multidisciplinary science mixing social science with engineering science, education programs are also very young compared to the education of traditional professions (like medicine, law and applied sciences professions like engineers) who are depending on one traditional and identified discipline. Although INSHPO, the International Network of Safety and Health Practitioner Organizations (Pryor, Hale, and Hudson 2015), considers that OHS (Occupational Health and Safety) is an emerging profession that is often not well defined, locally or globally, the safety profession in France can now be considered as a structured and recognized profession: several curriculums and descriptions of the safety or risk profession exist (APEC 2017; AMRAE 2013). This doesn't mean that before this period safety wasn't managed by professional people in organizations or companies; Ecole des Mines de Paris was founded by King Louis XVI in 1783 to ensure the management of the mines of the kingdom. Two issues in mining business were important at the moment, economy and safety. The school disappeared at the beginning of the French Revolution but was re-established by decree of the Committee of Public Safety in 1794. So engineers were trained to the traditional engineering disciplines (mathematics, physics, mechanics and chemistry) but also social sciences were developed and delivered, as economics and management.

The past years, a keen interest in "professionalization in/of safety » has emerged in the safety science community (Gilbert 2015). The FONCSI (Fondation pour une culture de sécurité industrielle) has initiated in 2015 a strategic analysis on "skills and competencies for industrial safety" in which several international researchers are involved (Bieder, Journé, and Laroche 2015; Bieder et al. 2018).

Professionalization in/of safety can be seen two ways: the professionalization of persons who will become experts in safety (professionalization in safety- PiS) and the integration of safety into the general professionalism of employees (professionalization of safety - PoS). Although Andrew Hale has worked since the eighties (Hale, Piney, and Alesbury 1986; Hale 1995; Booth, Hale, and Dawson 1991; Hale et al. 2005; Hale and Ytrehus 2004) on the topic of the professionalization of the profession (PiS), this renewed interest gives birth to new models and tools like the Australian OHS Body of Knowledge (Paul and Pearse 2016). This article will present a study of the professional context of a post master safety program's alumni.

The general research questions we want to tackle are the following: what is the career path of alumni of a post master program in risk management? Can we define their daily professional environment? Which knowledge and competencies are actually used? What is their position and role in an organization? What is the contribution of the post master program to their professionalism? How to develop better education in risk management to bridge the theory to the professional real life context? And in a very general way, what could be the safety professionals' contribution to safety?

In this article, we will introduce the context and the research methods with some early results. First, we will differentiate professionalization of and professionalization in safety. For information, we will use the concept of "safety professional" in this article, as "safety practitioner" is a person who is vocationally- 
educated where the safety professional is university-educated (or has attained a similar level of higher education) (Pryor, Hale, and Hudson 2015).

\section{Professionalization of safety}

Industry recently wonders if the amount of effort put into safety training of employees was worth it (Gilbert 2015). Although a lot of time and money is consecrated to safety trainings, accidents still occur. The professionalization of safety, the way how workers integrate safety issues in their daily work, is subject of attention of researchers. The concepts of ordinary and extra-ordinary safety have been developed by Claude Gilbert (Bieder et al. 2018). A new way of safety training is also a topic of interest. It is clear that the safety professional has a major role to play as he is the referee person for safety in the organization. Thus we see a clear link between professionalization " in " and " of " safety. This makes us wonder about the place of the safety professional in his organization. Gilbert states that the difficulties for good safety training program in a company (PoS) are that they have to fulfill internal performance obligations and requirements and external justifications (accountability).

\section{Professionalization in safety}

There is significant literature about safety professionals; Andrew Hale has done a lot of work since the eighties (see above), professional associations have also contributed to the subject (Pryor, Hale, and Hudson 2015) and even in the sixties, people (Scientifics) have written pertinent insights concerning the safety professional and his role in organizations that are still very actual today (Harper, Rockwell, and Weaver 1962). Scientific and professional courses have emerged since the seventies (Arezes and Swuste 2012). The last decennium, in France the curriculums who are dealing with risk management, safety or HSE (Health Safety and environment) grew in a significant way. Private organizations in France propose rankings of (business) education programs and since several years the category " risk management » exists (www.eduniversal-ranking.com). Last November, the author of this article for ESREL was solicited to review an article for Safety Science. Chinese contributors examined the professionalization of safety in China: "Development of safety science in Chinese higher education ». The last decade, we can observe a development of education of safety professionals in all industrialized countries.

Dekker investigated the role shaping factors about the safety profession (Provan, Dekker, and Rae 2017). This work is interesting because it can give an idea of the importance on a safety professional in his organization and the way how he can influence, model or create safety in the organization. This is a topic that has to be investigated and taught to future safety professionals. This present study tends to bring some answers to that question also. The following part presents our study object, the post master degree industrial risk management.

\section{Post Master Degree Industrial Risk Management}

In 1997, the top management of MINES ParisTech decided to launch a research department dedicated to risk and crisis with the mission of developing studies in cooperation with industrial partners and training activities. In 2002, the decision was taken to build a post-master program for training HSE professionals for the industry. 
The post master degree ("Mastère Spécialisé" in French) Industrial Risk Management was launched in 2004 on demand of French industry and in collaboration with Tongji University of Shanghai (China) to form, besides French students, also Chinese students on risk management for French companies developing in China.

The design of the curriculum was achieved from an analysis of academic literature and current practices, in close cooperation with companies' representatives, in order to fit the contents of the training and the pedagogical methods to the needs of the industrial sector. The program has known several important changes in organization and content while its existence. In the actual form (promotion 2017-2018), it contains 500 hours of courses during one year (begin October to end September). The rest of the time, students realize a professional mission with an industrial partner. The program forms future safety professionals in the occupational, environmental and industrial (process safety) field. The curriculum contains six main tracks:

- Safety regulations;

- Hazard and risk assessment;

- Safety Management Systems;

- Human and organizational aspects;

- Management and leadership aspects;

- Emergency and crisis management.

Lectures, exercises and practical work are provided and supervised by a faculty group composed of an equal number of academics and professionals.

Currently, 31 students attend the program; almost all of them alternate academic training and apprenticeship. This apprenticeship program consists in 5 weeks courses, 3 weeks enterprise, 3 weeks courses, 4 weeks enterprise, 3 weeks courses, 2 weeks enterprise, 1 week study trip, 5 weeks courses and 6 months enterprise followed by the defense in front of a jury of their professional project. The program in its current form contains six main tracks, a study trip (United Arab Emirates in 2017) and a professional conference, organized end of March by the students themselves.

The program has known an evolution from a « double degree or double competence " point of view to a program that forms " specialized " safety professionals. The students that apply for the program now have, for the great majority of them, already a Master degree in Health, Safety or Environment. The MS MRI makes them more "specialized", whereas in the past, students had degrees in chemistry, engineering, psychology or law. This is also the result of the increase in HSE Master Programs and the result of the demand of industry. Industry wants a student already trained in HSE for their professional missions and collaborations. This eliminates from the program the students who have no knowledge of risk and/or HSE. 
The scientific transfer of HSE findings to the industry takes some time. HSE practitioners often lack the knowledge of the genesis and relations between HSE theories and methods, models and metaphors developed since World War 2 (Swuste, Gulijk, and Zwaard 2010; Swuste et al. 2014). It is also important to know the evolution of the HSE job. The integration of a HSE professionals' training program in a dedicated research laboratory (CRC - MINES ParisTech) facilitates this knowledge transfer and informs the future HSE professionals of the latest advances in the field. They will probably keep an intellectual curiosity all the rest of their career and hopefully will participate in co-developing tools using the latest safety models (Besnard et al. 2009).

Post master programs are known to be "professionalizing "; the student will pass from the state of student to be a professional. Several characteristics of the MRI program tend to influence this transition: participation and courses of a lot of safety professionals, students pass a great deal of the program in the organization of their industrial partner, projects and case studies are real industry problems (with participation of industry), executive summaries are demanded on several topics, they work in teams, they do a lot of presentations, they learn to present their work to decision makers, the courses on "management and leadership" makes them aware of the importance of soft skills on the work floor.

The program has grown since 13 years to be more and more professionalizing. But finally, what is the contribution of the post master program to their professionalism? How to develop better education in risk management to bridge the theory to the professional real life context? For what kind of professional context do we prepare them? The next part will present the missions of a safety professional.

\section{Missions of the safety professional}

Several studies on the missions of safety professionals have been done. Wybo and Van Wassenhove (Wybo and Van Wassenhove 2016) present the missions of safety professionals (table 1), the needed skills to do the job and modeled the MRI program to correspond.

Table 1 : Missions of safety professionals in literature (Wybo and Van Wassenhove 2016)

\begin{tabular}{|c|c|c|c|c|c|c|c|c|c|}
\hline Job content topic & $\begin{array}{c}\text { ENSHPO } \\
2005\end{array}$ & $\begin{array}{c}\text { AMRA } \\
\text { E } 2013\end{array}$ & $\begin{array}{c}\text { ASSEF } \\
2007\end{array}$ & $\begin{array}{c}\text { Wu } \\
2011\end{array}$ & $\begin{array}{c}\text { INRS } \\
2004\end{array}$ & $\begin{array}{c}\text { De Joy } \\
1993\end{array}$ & $\begin{array}{l}\text { Hale } \\
2004\end{array}$ & $\begin{array}{c}\text { Kohn } \\
1991\end{array}$ & Total \\
\hline $\begin{array}{l}\text { Advising management and } \\
\text { decision makers }\end{array}$ & ++ & & + & & & ++ & + & & 6 \\
\hline $\begin{array}{l}\text { Definition of the missions and } \\
\text { the organization of the safety } \\
\text { management system }\end{array}$ & ++ & + & + & & & + & + & & 6 \\
\hline $\begin{array}{l}\text { Risk management (hazard } \\
\text { identification, evaluation and } \\
\text { control) }\end{array}$ & +++ & + & +++ & + & ++ & +++ & ++ & +++ & 18 \\
\hline Regulatory compliance & ++ & & + & + & & & + & ++ & 7 \\
\hline $\begin{array}{l}\text { Diffusion of safety culture and } \\
\text { culture change }\end{array}$ & ++ & + & & + & & & ++ & & 6 \\
\hline Training and communication & ++ & & + & + & + & ++ & + & ++ & 10 \\
\hline Accident and incident & ++ & & + & & + & + & + & ++ & 8 \\
\hline
\end{tabular}




\begin{tabular}{|l|c|c|c|c|c|c|c|c|c|}
\hline investigation & & & & & & & & & \\
\hline $\begin{array}{l}\text { Emergency and crisis } \\
\text { management }\end{array}$ & ++ & + & + & + & + & & & ++ & $\mathbf{8}$ \\
\hline Monitoring and reporting & ++ & + & ++ & + & + & + & + & ++ & $\mathbf{1 1}$ \\
\hline Knowledge management & ++ & & & + & + & & & & $\mathbf{4}$ \\
\hline Insuring and costing risks & ++ & + & & + & & & & & $\mathbf{4}$ \\
\hline
\end{tabular}

They conclude by proposing requirements for a HSE professional training curriculum: students getting their degree in HSE must be fully operational and demonstrate their professionalism when they start their first job. So the curriculum must prepare them to their future work. From the literature review and the analysis of a HSE professional's job content, they identified the important matters our HSE professional's curriculum must address:

- Domains to teach:

- Regulations and HSE management systems;

○ Hazard and Risk analysis in occupational health, system safety and environment;

- Human and organizational matters;

Emergency and crisis management;

○ Communication, management and leadership;

- A strong implication of safety professionals;

- The use of realistic case studies;

- Interactions with industry practitioners:

○ "Field work" in industrial sites;

- Annual conference for industry practitioners;

- A long internship/presence in a company;

Nevertheless, questions still remain on other aspects of their professional context. What are the knowledge and the competencies they mobilize? What is their position and role in an organization? What is their vision of safety and what can be their contribution to safety? A first step is to look closer to what alumni of a post master program in risk management do once graduated. We developed a methodology to search for some first answers.

\section{Methodology: general questionnaire}

The post master program MRI has now about 200 alumni. To investigate the professional context of the safety professional, we dispose of exactly 197 persons to consult. 
A similar study on the context of a profession has been conducted in the Netherlands (Corporaal et al. 2016). They investigate the Human Resources (HR) professional and they use the following methodology: several students (544 students participated to the study) have asked HR professionals (571 persons), their hierarchical boss (542 persons) and a line manager (553 persons) to fulfill a questionnaire. That questionnaire was used afterwards as guide to do in-depth interviews with those persons. This study is repeated yearly (!). Every four years, a synthesis is done and an education profile is created. This profile enables to adapt the curricula of the HR programs. The research themes are the missions of the HR professional, role and position of the HR professional, competencies needed for the HR professional and the relations with line management.

In the field that interests us, the OHS Professional Capability Framework is a framework for practice developed by the International Network of Safety and Health Practitioner Organizations (Pryor, Hale, and Hudson 2015). INSHPO differentiate competence and capability. The difference between competency and capability is that competency is about delivering the present based on the past, while capability is about imagining and being able to realize the future. Capability goes much further than competency, it's also about confidence and adaptability. For our study, we use "competency". With the first results, we will see and judge if there is a need to differentiate between competency and capability.

From the literature, personal work and observations, a general questionnaire was developed. This development was done with the support of co-researchers (Gilbert De Terssac, sociologist, research director CNRS) and was tested on some alumni. The remarks were integrated into the questionnaire. The questionnaire was proposed to the alumni through an on-line version. Each alumnus was personally contacted mid November 2017 by email with the request to take some time to answer the questions. The time to respond is set to two months. Several solicitations are done; the aim is to have at least 100 responses. To answer all questions, the participant has to take at least 30 minutes of his time and has to do some critical analysis of his work situation. Answering the questionnaire takes a real effort.

The questionnaire is structured as followed:

- questions about the identity

- career description

- job description

- benefits of the MRI program for the professional career

- comments

The job description is the most important for our research questions and is composed of twelve questions. Four questions are very important, we will present them here.

One question concerns the missions of the professional. From a synthesis from the literature, personal observations and discussions with safety professionals, fourteen missions are proposed (table 2). For 
each mission, the respondent has to notify on a scale going from 1 (not important) to 10 (very important) the importance of the mission in his current job, according to several levels:

- according to his or her personnel conviction

- according to the organization in which he or she is working (his superiors)

- according to the real time he or she spent on the mission

In this way, we can identify discordances between the professional and his organization.

Table 2: The fourteen missions of the safety professional

\begin{tabular}{|ll|}
\hline \multicolumn{1}{|c|}{ Missions of the safety professional } \\
\hline 1. & Inform and advice the direction \\
\hline 2. & Organize the safety management system \\
\hline 3. & Follow up of regulations \\
\hline 4. & Control compliance with regulations \\
\hline 5. & Manage risks (identification / evaluation / treatment) \\
\hline 6. & Develop safety culture \\
\hline 7. & Inspections on the work floor, organizing information collection (bottom up) \\
\hline 8. & Train and communicate about safety and risk \\
\hline 9. & Analyze incidents and accidents \\
\hline 10. Manage crises and emergencies \\
\hline 11. Measure performance: monitoring and reporting \\
\hline 12. Give expertise for a specific type of risk \\
\hline 13. Manage the insurance and financial side of risks \\
\hline 14. Realize business continuity plans \\
\hline
\end{tabular}

The second important question concerns the characteristics of the professional's job (Table 3). Sixteen descriptions of work characteristics are proposed. The professional is asked to score 1 (not agree) to 10 (totally agree) for each situation.

Table 3: Job characteristics description

\section{Characteristics of the job}

1. Presence of an administrative workload and an important "safety bureaucracy"

2. A big diversity of objects and subjects to handle

3. A lot of subjects to handle with urge

4. No time to treat subjects in depth

5. A lot of traveling

6. A lot of simultaneous missions with different deadlines

7. Recognition of the direction

8. Recognition of middle management and workers

9. Feeling of being isolated in an organization that is not much concerned by safety 
10. Interruptions and adaptations of planning

11. Difficulties to conciliate safety prevention with regulatory compliance, requirements of inspection of the administration and the politics of the organization

12. Interactions with a lot of stakeholders

13. Lack of means

14. Necessity to adapt constantly the rules (theory) to the reality of the work floor (practice)

15. Frequent interactions with the work floor

16. Autonomy and liberty of initiative

The third question is about the concept of safety. Twenty-two ideas are formulated about what contributes to safety (table 4). The professional has to score (1 not important and 10 very important) the ideas according to his personal conviction and according to what he thinks is the conviction of his organization.

Table 4: Safety "ideas"

\begin{tabular}{|c|}
\hline Composantes de la sécurité \\
\hline 1. Engagement of the direction \\
\hline 2. Engagement of middle management \\
\hline 3. Compliance with regulations \\
\hline 4. Safety culture \\
\hline 5. Safe technical conception \\
\hline 6. Bottom up consultation \\
\hline 7. Consultation of administration and inspection \\
\hline 8. Consultation and information of the neighborhood living near the company \\
\hline 9. Presence of a Safety Management System \\
\hline 10. Safety training \\
\hline 11. Team spirit and cooperation on the work floor \\
\hline 12. Respect of procedures \\
\hline 13. Sharing of good practices \\
\hline 14. Sharing of information on accidents and incidents \\
\hline 15. Comprehension and modeling of hazards \\
\hline 16. Presence of a degree of liberty in interpreting procedures in function of the context \\
\hline 17. Analysis of root causes after an accident \\
\hline 18. Considering the variability of human performance by analyzing the work conditions \\
\hline 19. A good technical knowledge of the system by the stakeholders \\
\hline 20. Human error analysis \\
\hline 21. Give sense to work : organize debates on work situations \\
\hline 22. Organize crisis and emergency exercises \\
\hline
\end{tabular}

The fourth question (table 5) concerns knowledge and competencies (skills or even capabilities) mobilized by the professional and the competencies that he or she would like to mobilize more. It should be noticed that knowledge and learning can be characterized at six levels. These levels are based on the 
well-known Bloom taxonomy (Murtonen, Gruber, and Lehtinen 2017) and go from 'simple' remembering to 'elaborated' evaluating. But we can consider the levels of analyzing, synthetizing and evaluating as hierarchical equal levels.

- Remembering (knowledge)

- Understanding (comprehension, translating, interpreting or extrapolating information)

- Applying (using principles or abstractions to solve novel or real-life problems)

- Analyzing (breaking down complex information or ideas into simpler parts to understand how the parts relate or are organized)

- Synthesizing/creating (creation of something that did not exist before)

- Evaluating (judging something against a given standard)

A safety professional who is fully competent is expected to operate minimum at level three (applying knowledge) for every knowledge category (Pryor, Hale, and Hudson 2015).

Skills can be categorized in three sections: personal skills (example: verbal communication), professional practice skills (example: problem solving and critical thinking) and professional technical skills (example: implements tools to assess risk). We chose to list in table four knowledge and skills but with differentiating neither the type of skills nor the taxonomy of Bloom. The last item of the list, 'ethics', is rather a personal value than a skill. Those aspects will be studied more in depth when doing interviews with selected people (see below).

Table 5: Knowledge and competencies

\begin{tabular}{|c|}
\hline Knowledge and competencies \\
\hline 1. Knowledge of regulations \\
\hline 2. Knowledge of hazards \\
\hline 3. Knowledge of the technical system \\
\hline 4. Knowledge of accident models and theories \\
\hline 5. Knowledge of risk analysis methods \\
\hline $\begin{array}{l}\text { 6. Knowledge of business management: finance, human resources, organization, } \\
\text { technologies, innovation... }\end{array}$ \\
\hline 7. Competency of applying risk analysis methods \\
\hline $\begin{array}{l}\text { 8. Competency of « constructing " a risk analysis methodology adapted to the } \\
\text { problem }\end{array}$ \\
\hline 9. Competency of crisis and emergency management \\
\hline 10. Competency of situation/activity/accident analysis \\
\hline 11. Competency of translation of politics into real actions \\
\hline 12. Competency of translation of accidents statistics into action plans \\
\hline 13. Competency of strategic planning \\
\hline 14. Competency of hierarchizing problems \\
\hline 15. Competency of looking for the right information and learning \\
\hline
\end{tabular}


16. Competency of critical analysis

17. Competency to propose solutions

18. Competency of written and spoken communication

19. Competency of synthetizing and adapting of wording to the public addressed

20. Competency of organizing personal work

21. Competency of listening

22. Competency of leadership

23. Competency of being exemplary

24. Competency of teamwork

25. Competency of working in an multicultural organization

26. Competency of using new communication technologies

27. Ethics

The next paragraph will present some first results and a discussion about how to complete this methodology (the questionnaire).

\section{First results, discussion and perspectives}

The questionnaire is on-going and at this date, 61 alumni of the 197 persons contacted have responded and completed the questionnaire. To complete the questionnaire (the majority of questions are compulsory) at least 30 minutes and a great effort of reflecting on professional practices is needed. Another 50 respondents started but didn't finalize the questionnaire yet. The aim is to have about $70 \%$ of the alumni. Each alumnus will be contacted individually, and several times if necessary.

Several biases are present for this study. We will discuss the most important ones.

We find that the youngest alumni completed in priority the questionnaire. The elder ones 'lost' probably the implication with their former school and are less motivated to respond. Also, several contact addresses of the elder alumni are obsolete. A work to trace them on Linked In is ongoing. The Chinese alumni are also difficult to contact. This could give a slightly distorted image because we will have only data from young professionals: the description of the professional context of a junior safety professional.

The curriculum of the program has been modified all along its existence. Several important modifications have been done: in 2010 an important content modification, in 2014 the introduction of alternate training and apprenticeship. The respondents will evaluate a program that was not the same for all the alumni. We hope that the first results will give us insights on the importance on professionalization of the introduction of the alternate training and apprenticeship with an industrial partner in the curriculum.

A complementary methodology will allow us to gather more data. The first results will able us to organize focus groups with alumni to discuss several aspects or findings. A couple of monographies will be done also: a safety professional, his superior and his colleagues will be interviewed and observed in their daily work. It could be interesting to interview also line managers who are in contact with the safety professional.

The findings of this work will able us to: 
- $\quad$ Have an idea of the careers of our alumni (company, wages, function,...)

- Have an idea of the professional context of our safety alumni (missions, job profile, organizational culture...)

- Have an idea of the knowledge and competencies they mobilize

- Have an idea of the impact of the MRI program on their professionalism

The perspectives of this work are of different nature. On one hand we continue to implement changes and modifications and we improve the program of MRI to prepare the students to the "real life" context of the safety professionals' job. This is managed by new pedagogical approaches: role plays, case studies, close interactions with safety professionals and collaboration of Safety Scientifics and Safety Professionals together on the same project. We discussed in a former paper (Wybo and Van Wassenhove 2016) the pedagogy used for education of safety professionals. The present study will be able to bring some data for improving the pedagogic approaches of the program.

In order to improve the program, we must absolutely question ourselves on the ways we evaluate the program. The four-level training evaluation model of Kirkpatrick (Gilibert and Gillet 2010) is widely known. We could think of integrating a yearly survey of alumni and/or interview and observation of alumni in work conditions in a general evaluation plan based on Kirkpatrick's model. Kirkpatrick proposes four levels of evaluation of learning: reaction (satisfaction of learners), learning (what knowledge do they acquire, behavior (do they use the new knowledge in work situation) and results (outcome for the organization). Paul Swuste (Swuste and Sillem 2018) is interested in the quality approach to evaluate a post academic course 'management of safety, health and environment'. Having a feedback of alumni is not enough to have a global evaluation of the program.

What is the goal to form and educate students in safety curricula? Teaching them theoretical risk analysis methods (HAZOP, FMECA, QRA...)? Preparing them to the real world problems when applying those approved methods? Maybe the role of an education program is also to form "new" professionals who are importing new (scientific) insights into the profession. They are the bridge between science and practice. Probably, it is all this and even more.

Last but not least, in our understanding of safety in organizations, the role of the safety professional is very important. David Provan (Provan, Dekker, and Rae 2017) did a literature review of the factors shaping the role of a safety professional (bureaucracy, influence and beliefs). This present study will certainly contribute to identify some factors. Being aware of those factors will surely enable future safety professionals to be more effective in their job: bringing more safety to our world. And this is exactly the fourth level of Kirkpatrick's evaluation model.

\section{References}


AMRAE. 2013. "Referentiel Metier Risk Manager."

APEC. 2017. "Les Offres d'emploi Cadre Dans Le Domaine Des Risques Industriels." Les Études de l'emploi Cadre, February.

Arezes, Pedro M., and Paul Swuste. 2012. "Occupational Health and Safety Post-Graduation Courses in Europe: A General Overview." Safety Science 50 (3):433-42. https://doi.org/10.1016/j.ssci.2011.10.003.

Besnard, Denis, Damien Fabre, Wim Van Wassenhove, and Eduardo FA Runte. 2009. "An Account of Scientific Transfer to the Industry: The Co-Development of an Incident Analysis Tool." In 9th Conference of the European Sociology Association.

Bieder, Corinne, Claude Gilbert, Benoît Journé, and Hervé Laroche, eds. 2018. Beyond Safety Training. SpringerBriefs in Applied Sciences and Technology. Cham: Springer International Publishing. https://doi.org/10.1007/978-3-319-65527-7.

Bieder, Corinne, Benoît Journé, and Hervé Laroche. 2015. "Analyse Stratégique Professionnalisation et Sécurité: Méthode \& Pistes de Réflexion."

Booth, R. T., Andrew Richard Hale, and S. Dawson. 1991. "Identifying and Registering Safety Practitioners." Safety Science 14 (3):231-240.

Corporaal, S., M. Vos, T. Morssink, S. Peters, and N. van Dartel. 2016. "De HRM Praktijkmonitor." Samenwerkende lectoraten HRM, Holland.

Gilbert, Claude. 2015. “La Sécurité: Une Affaire de 'Professionnels'?" Tribunes de La Sécurité - FONCSI, no. $\mathrm{N}^{\circ} 6$ (June).

Gilibert, Daniel, and Isabelle Gillet. 2010. "Revue Des Modèles En Évaluation de Formation: Approches Conceptuelles Individuelles et Sociales." Pratiques Psychologiques 16 (3):217-238.

Hale, A. R. 1995. "Occupational Health and Safety Professionals and Management: Identity, Marriage, Servitude or Supervision?," no. 20:233-45.

Hale, A. R., G. Bianchi, G. Dudka, W. Hameister, R. Jones, P. Perttula, and I. Ytrehus. 2005. "Surveying the Role of Safety Professionals: Objectives, Methods and Early Results." Safety Science Monitor 9 (1). http://www.enshpo.eu/userfiles/Safety\%20Science\%20Monitor\%202005(2).doc.

Hale, A. R., M. Piney, and R. J. Alesbury. 1986. "The Development of Occupational Hygiene and the Training of Health and Safety Professionals." The Annals of Occupationnal Hygien 30 (1).

Hale, A. R., and I. Ytrehus. 2004. "Changing Requirements for the Safety Profession: Roles and Tasks, Journal of Occupational Health and Safety." Journal of Occupational Health and Safety, no. 20:23-36.

Harper, George W., Thomas H. Rockwell, and D.A. Weaver. 1962. "The Safety Engineer -What Do We Expect of Him? - What Knowledge Does He Need? - How Do We Upgrade His Performance?" ASSE Journal VII (2).

Murtonen, Mari, Hans Gruber, and Erno Lehtinen. 2017. "The Return of Behaviourist Epistemology: A Review of Learning Outcomes Studies." Educational Research Review 22 (November):114-28. https://doi.org/10.1016/j.edurev.2017.08.001.

Paul, Gunther, and Warwick Pearse. 2016. "An International Benchmark for the Australian OHS Body of Knowledge (BoK)." Safety Science 81 (January):13-24. https://doi.org/10.1016/j.ssci.2015.07.016.

Provan, David J., Sidney W.A. Dekker, and Andrew J. Rae. 2017. "Bureaucracy, Influence and Beliefs: A Literature Review of the Factors Shaping the Role of a Safety Professional." Safety Science 98 (October):98-112. https://doi.org/10.1016/j.ssci.2017.06.006.

Pryor, Pam, A. R. Hale, and D. Hudson. 2015. "The OHS Professional: A Framework for Practice - Role, Knowledge and Skills." International Network of Safety and Health Practitioner Organisations (INSHPO). Park Ridge, IL, USA. 
Swuste, Paul, Coen van Gulijk, and Walter Zwaard. 2010. "Safety Metaphors and Theories, a Review of the Occupational Safety Literature of the US, UK and The Netherlands, till the First Part of the 20th Century." Safety Science 48 (8):1000-1018. https://doi.org/10.1016/j.ssci.2010.01.020.

Swuste, Paul, Coen van Gulijk, Walter Zwaard, and Yvette Oostendorp. 2014. "Occupational Safety Theories, Models and Metaphors in the Three Decades since World War II, in the United States, Britain and the Netherlands: A Literature Review." Safety Science 62 (February):16-27. https://doi.org/10.1016/j.ssci.2013.07.015.

Swuste, Paul, and Simone Sillem. 2018. "The Quality of the Post Academic Course 'management of Safety, Health and Environment (MoSHE) of Delft University of Technology." Safety Science 102 (February):26-37. https://doi.org/10.1016/j.ssci.2017.09.026.

Wybo, Jean-Luc, and Wim Van Wassenhove. 2016. "Preparing Graduate Students to Be HSE Professionals." Safety Science 81 (January):25-34. https://doi.org/10.1016/j.ssci.2015.04.006. 